Boise State University ScholarWorks

Public Policy and Administration Faculty

Publications and Presentations

Department of Public Policy and Administration

9-1-2017

\title{
Tracking State Trends in Environmental Public Opinion
}

Luke Fowler

Boise State University

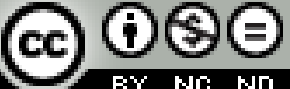

This is an author-produced, peer-reviewed version of this article. (C) 2017, Elsevier. Licensed under the Creative Commons AttributionNonCommercial-NoDerivatives 4.0 International license. http://creativecommons.org/licenses/by-nc-nd/4.0/. The final, definitive version of this document can be found online at The Social Science Journal, doi: 10.1016/j.soscij.2017.02.003 


\section{Tracking State Trends in Environmental Public Opinion}

Abstract: Trends in state-level public opinion on the environment within the U.S. are examined, using data from the General Social Survey (GSS) from 1976 to 2008. Multilevel Regression and PostStratification (MRP) approach estimates public support for environmental spending at the U.S. statelevel over three decades. This allows for an analysis of inter-state homogeneity of environmental public opinion, over the latter half of the twenty century. The findings indicate state-level trends mirror those at the national-level, but state-level public opinion is becoming more analogous over time.

Keywords: public opinion, environmental policy, multi-level modeling

\section{Introduction}

Well-tracked are United States (U.S.) national-level trends in environmental public opinion since the early 1970s (Daniels, Krosnick, Tichy, and Tompson, 2013). While interest groups and experts voiced a concern over environmental conditions previously, widespread general public support did not emerge until the mid-1960s (Erksine, 1972; Dunlap 1991, 1995; Daniels et al., 2013). This was in response to mobilization of interest groups and political leaders, culminating in Earth Day's establishment in 1970 (Erksine, 1972; Dunlap, 1995). Over the next decade, though, there was a slight decline in public support as issue salience faded. New environmental policies based in lax regulation, reductions in federal environmental efforts, and devolution of policy implementation caused a ground swell of environmental activism led to a resurgence of environmental support in the 1980s, peaking in 1990 with Earth Day's $20^{\text {th }}$ anniversary (Dunlap, 1991, 1995; Daniels et al., 2013). Afterwards, fading concern for traditional environmental issues, as air, water, and land quality caused public support to subside to moderate levels and remained stable until the early 2000s (Andrews, 2006; Bosso and Guber, 2006; Nordhaus and Shellenberger, 2007; Daniels et al., 2013). Since the mid-2000s, a marginal increase in public support has occurred, due to new environmental issues such as climate change (Daniels et al., 2013). However, only a single survey item strictly follows this general pattern: support for environmental spending. Figure 1 displays the percentage of General Social Survey (GSS) respondents from 1974 to 2010 that responded the U.S. is spending too little, about the right amount, or too much 
on the environment, which is consistent with the described pattern from previous scholarship (Smith, Marsden, Hout, and Kim, 2013). Other items tracking environmental public opinion tend to follow a relatively similar pattern; though, variation exists. Extant literature supports the general trend outline above as the best approximation and most policy scholars contend the spending item is the best articulation of environmental public attitudes (Daniels et al., 2013).

Figure 1. National Trends of Public Opinion on Environmental Spending, 1974-2010

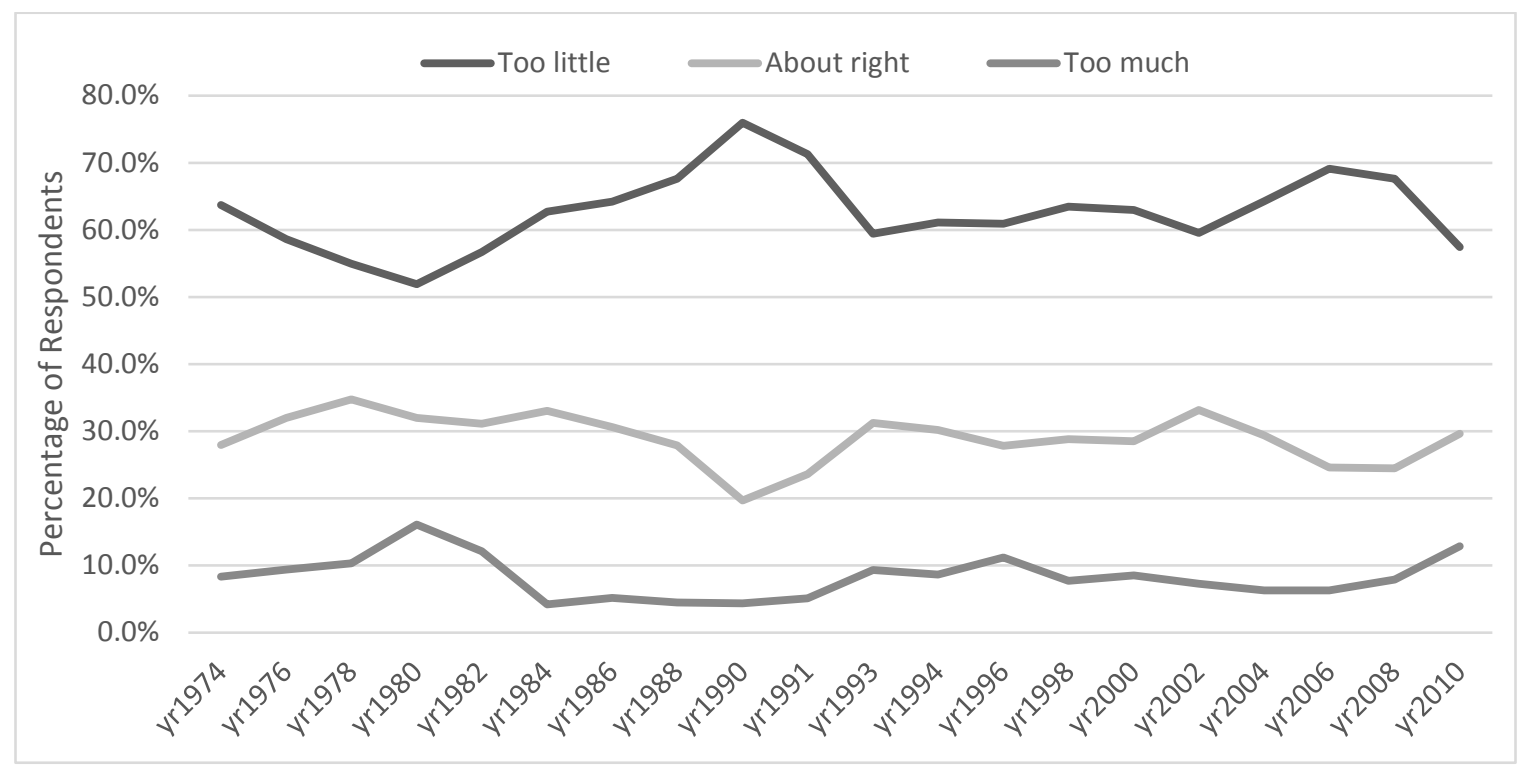

National trends only tell part of the story of environmental policy. There is far less tracking of state-level public opinion and fewer analyses of variability. State-level trends are particularly significant in environmental policy as states enjoy considerable control and responsibility in both their own policymaking and federal program management (Ringquist, 1993). Congress adopted all legislation, which makes up the backbone of U.S. environmental policy such as Clean Air Act (CAA), Clean Water Act (CWA), Safe Drinking Water Act (SDWA), and Resource Conservation and Recovery Act (RCRA) (ECOS, 2014). However, states make up the constituencies for both the U.S. House of Representatives and U.S. Senate, so it goes to reason state-level public opinion would have impacts that are more direct on 
members of Congress than national public opinion (Bartels, 1991). Specific to environmentalism, evidence is contradictory with some scholars finding environmental issue salience is not strong enough to effect voting behavior when considering trade-offs with economics (Ladd and Bowman, 1995; Repetto, 2006; Daniels et al., 2013). Nevertheless, with environmental spending, there is strong support to suggest spending priorities are an issue that drives voter behavior, and there are connections between state-level public opinion and Congressional voting patterns (Alvarez and Nagler, 1998; Davis and Wurth, 2003; Davis, Wurth, and Lazarus, 2008; Daniels et al., 2013; Fowler, 2016). Furthermore, states serving as "laboratories of democracy" have the opportunity to go beyond the minimum standards set by the federal government. Extant scholarship well documents these policy experiments and the subsequent trends in distribution (Tarr, 2001; Volden, 2006; Lowery, Gray, and Baumgartner, 2011; Shipan and Volden, 2012). The "race to the top" has resulted from localized socio-economic and political factors, which value the social and economic benefits associated with a cleaner environment (Hanemann, 2007; Fowler and Breen, 2013, 2014; Rabe, 2013).

Finally, most major federal environmental programs rely on state governments for implementation, with all 50 states having delegated authority over CAA programs; 46 states, over CWA programs; 49 states, over SDWA programs; and 48 states, over RCRA programs (ECOS 2014). While there is a common set of standards, policy outcomes largely vary, with scholars connecting these results to socio-economic and political factors including public opinion (Ringquist, 1993; Sapat, 2004; Hoornbeek, 2005; Woods, 2006). Thus, state-level public opinion has large implications for policy processes as states represent the level where variation in efforts and support occurs. Furthermore, socio-economic and environmental conditions heavily influence environmental public opinion, as well as political actions from advocacy groups and the government (Daniels et al., 2013). None of those factors has remained static between states over time. These variations can have important implications for understanding policymaking and administration in this area, especially as it relates to policy distribution 
and innovation. Across policy areas, states tend to follow national trends but exhibit heterogeneity at the same time (Pacheco, 2014). While it is likely states will follow the same general pattern in environmentalism, there is significant room for variation between states and within years.

\section{Methodology}

\section{Estimating State-Level Public Opinion}

While aggregation techniques have been popular in the past, they have come under criticism for lack of sophistication and high potential for biased estimates for small states or for missing temporal shifts when data is pooled over long periods of time. To compensate for those shortcoming, Multi-level Regression and Post-Stratification (MRP) was developed to provide a method of better utilizing all the information in a dataset to provide more accurate estimations using smaller sample sizes over shorter periods of time. MRP uses a multi-level model of demographic and geographic predictors to estimate individual responses within a population, and then weights those estimations based on actual populations. According to Lax and Phillips (2009b), "in this way, all individuals in the survey, no matter their location, yield information about demographic patterns which can be applied to all state estimates, and those residents from a particular state or region yield further information as to how much predictions within that state or region vary from others after controlling for demographics" (p. 109).

The process involves three steps. First, we estimate multi-level models from predictor variables (Park, Gelman, and Bafumi 2006; Lax and Phillips 2009b; Pacheco 2011; Warshaw and Rodden 2012). Multi-level modeling in its simplest form is an extension of ordinary least squares (OLS) regression. MLM models the relationship within each group at the lower levels and the variation between groups at all levels. As a result, relationships are modeled for each group at each level (Bryk and Raudenbush 1992; Hofmann 1997; Raudenbush and Bryk 2002; Bickel 2007). At level-1, the equation mirrors a simple OLS regression equation: 


$$
Y \_l \alpha=\beta \_0 \alpha+\beta \_1 \alpha X \_l \alpha+r \_l \alpha
$$

where $\gamma_{-} \iota \alpha$ is the outcome for individual $\mathrm{\iota}$ in group $\alpha, X_{-} \iota \alpha$ is the value of the predictor individual $\mathrm{t}$ in group $\alpha, \beta \_0 \alpha$ and $\beta \_1 \alpha$ are the intercepts and slopes estimated separately for each group, and $r \_l \alpha$ is the residual. However, since the relationships are estimated for each group separately, the slopes and intercepts can be stable or vary. At level-2, the regression model uses the slopes and intercepts of the level-1 model as dependent variables, and the level-2 variables as the independent variables. In simpler terms, the level-2 variables predict the differences in the relationships between level-1 variables and outcomes. At level-2, the equation takes on a more complex form:

$$
\begin{aligned}
& \beta \_0 \alpha=\nu_{-} 00+\nu_{-} 01 \mathrm{G} \_\alpha+U \_0 \alpha \\
& \beta \_1 \alpha=v_{-} 10+v_{-} 11 \mathrm{G} \_\alpha+U_{-} 1 \alpha
\end{aligned}
$$

where $\beta \_0 \alpha$ and $\beta \_1 \alpha$ are the intercepts and slopes estimated separately for each group from level-1 and serve as the dependent variables, $G_{-} \alpha$ is a group level variable, $\nu_{-} 00$ and $\gamma_{-} 10$ are the second stage intercept terms, $\nu_{-} 01$ and $\nu_{-} 11$ are the slopes relating $G_{-} \alpha$ to the intercept and slope terms from the level-1 equation, and U_0 $\alpha$ and $U \_1 \alpha$ are the level-2 residuals (Bryk and Raudenbush 1992; Hofmann 1997; Raudenbush and Bryk 2002; Bickel 2007).

Statistical assumptions of MLM are comparable to that of OLS; however, they differ slightly due to multiple levels of analysis. The assumptions are: 1 ) at each level, linearity; 2) at level-1, residuals are constant, independent from level-1 predictors, and have a normal distribution; 3) at level-2, random errors have a multivariate normal distribution, and uncorrelated residuals; and 4) independence of observation only at the highest level, not within nested groups (Hofmann 1997; Chaplin 2003; Bickel 2007; ATS 2012). These assumptions are more flexible than those for OLS; nevertheless, when violated, MLM still produces a best-fit model similar to the Best Linear Unbiased Estimate property for an OLS model (Chaplin 2003). These same issues apply to multi-level logistic regression models, but comparison between OLS and MLM makes differences easier to highlight (Park, Gelman, and Bafumi 2006; Bryk and 
Raudenbush 1992; Hofmann 1997; Raudenbush and Bryk 2002; Bickel 2007). However, our analysis employs logistic models, as it relies on a dichotomous dependent variable.

Second, using the multi-level models, we make estimations for each potential 'person type' in the dataset based on coefficient estimates. Whether actually observed in the dataset or not, a person type is every possible individual group, based on the variables in the model (Pacheco 2011). For example, using two dichotomous variables sex (male, female) and race (black, white), we can identify four potential person types: male-black, male-white, female-black, female-white. When using this technique for state-level estimates, each state represents a different person type for each demographic group (i.e., Florida-male-white, Georgia-male-white, etc.). After imputation, there is a coefficient estimate for each potential person group that represents the likelihood of a person that fits into that specific group having a certain response to the survey item (Pacheco 2011). Third, post-stratification weights are created to weight the coefficient estimates for each person type against the actual population to control for any demographic biases (Park, Gelman, and Bafumi 2006; Lax and Phillips 2009b; Pacheco 2011; Warshaw and Rodden 2012). The estimate of each person type is weighted against the actual frequency of that person type in the population. This produces a single estimate for each state based on the demographics of the state. In this case, the coefficient estimates are logistic coefficients so the estimates reflect the probability of moving from the base category.

Theoretically, the MRP approach produces more accurate and purer estimations of state-level public opinion than the aggregation approach by considering demographic differences across US states (Park, Gelman, and Bafumi 2006; Lax and Phillips 2009a; Lax and Phillips 2009b; Pacheco 2011; Warshaw and Rodden 2012). More importantly, though, Warshaw and Rodden (2012) tested the statistical effectiveness of MRP compared to aggregation. The findings strongly indicate that MRP outperforms the aggregation technique along many lines, and produces much more accurate estimations of statelevel public opinion. However, as sample sizes grow, these differences are reduced. With MRP much 
smaller datasets can estimate public opinion at the Congressional district level $(2,500+)$ or even the state legislative district level (5,000+) (Warshaw and Rodden 2012). Thus, the MRP approach is both theoretically and statistically superior to the aggregation approach.

\section{Data}

GSS provided public opinion data from 1973 to 2010 . GSS data was used as it is one of the few polling data sources that has consistency over time in survey items and polling techniques, and poll samples that include respondents from the majority of states every year. GSS used two alternative versions of the environmental spending item. The more frequent version: "are we spending too much, too little, or about the right amount on improving and protecting the environment?;" and the less frequent version: "are we spending too much, too little, or about the right among the environment?" (Smith et al., 2013). As these questions are relative to actual levels of spending, they function similar to Stimson, Mackuen, and Erikson's (1995) measure of mood, rather than a pure estimate of public opinion. That is, the question is not asking objectively if we should spend on the environment but rather if we should spend relative to the actual amount being spent, so the responses are a function of both public support for environmentalism and perceptions of actual spending. With no respondents asked the same question, the more frequent version includes 30,644 responses from 1973 to 2008, the less frequent version, 18,180 responses from 1984 to 2010 (Smith et al., 2013). Both versions displayed similar national patterns. To maximize observations, we combined items into a single item and recoded responses into a dichotomous variable, with pro-environmental as one and opposition as zero. ${ }^{1}$ National Opinion Research Center (NORC) conducted GSS every year from 1973 to 1994, with 1981 and 1992 as exception, and then every two years subsequently. After 1994, GSS used larger survey samples, so the biennial sample size tends to be equivalent to two years of previous surveys (Smith et

\footnotetext{
${ }^{1} 1=$ too little, $0=$ about the right about and too much.
} 
al., 2013). While MRP performs well with small datasets, more data produces better estimates.

Additionally, single year items can be biased by irregularities in process or contemporary events. To deal with these issues, surveys were pooled over a five year period, and estimates were produced for every even year from 1976 to $2008 .^{2}$ A five-year period was chosen to compensate for the gaps in annual data due to the later biennial surveys. This allows enough data to be pooled to reduce bias between survey samples but still capture any potential changes occurring over time. However, this does reduce the potential to observe dramatic shifts in opinion. Since limited observations at the state-level are a greater threat to validity here than the potential to miss large shifts over time, a larger temporal pool was selected to best reduce validity concerns. This creates a sample size of between 4547 and 8311 for each year's estimates. If there were no survey respondents for a state in a given year, the state was dropped from the dataset for that year. States included in the sample ranges from 34 to 46 (See appendix A for a list of missing data by state and year).

At level-1 of the multi-level models, we use four demographic variables: sex (male and female); age (18-29, 29-44, 45-65, and 65+); race (white, non-white); and, degree (no high school, high school, some college, college or more). We identified level-1 variables based on previous scholarship of demographic and social bases in the formation of public opinion in general and environmental politics specifically (Erikson and Tedin, 2010; Pacheco, 2011, 2014; Daniels et al., 2013). ${ }^{3}$ At level-2, states are control variables. ${ }^{4}$ Some scholarship suggests including other level-2 variables enhances estimate reliability (Stollwerk, 2012). However, MRP scholarship is still limited in its analyses of these effects, so we chose not to include other level-2 variables. There is certainly a trade-off in that decision, but we erred on the side of caution and limited variable selection in the interest of parsimony. Finally, we

\footnotetext{
2 For example, estimates for 1976 include data from 1974, 1975, 1976, 1977, and 1978 surveys; while estimates for 2004 include data from 2002, 2004, and 2006 surveys.

${ }^{3}$ Other demographic variables were not included in the final estimations for one of two reasons. First, insufficient data was available from either the GSS or US Census. Second, the variable was inconsequential to the analysis, mostly due to a lack of statistically significant results.

${ }^{4}$ District of Columbia is included in the estimation models to maximize observations.
} 
calculated post-stratification weights based on data from U.S. Census and applied those to the coefficient estimates for each group (Census, 2016). ${ }^{5}$ The reported estimates are weighted logistic coefficients that represent the likelihood of states moving from the spending too much or about the right amount category to the spending too little category, with the higher the value meaning the higher the likelihood of the state being pro-environmental.

\section{Results}

State estimates indicate there are two notable trends. First, states essentially follow the same reported national trend, but there are substantive differences between states. Figure 2 illustrates this by tracking five randomly selected states: Arizona, Georgia, Kansas, Minnesota, and Pennsylvania. Public support for spending on the environment is lowest in the late 1970s and early 1980s, but experiences a steady incline through the 1980s. Then, support peaks around 1990, and drops considerably until the mid-1990s. Finally, support appears to stabilize from the late 1990 s through the 2000s, with an uptick after the mid-2000s. Nevertheless, there is significant state-level variation. On average, states experienced a 0.852 range of public opinion estimates from 1976 to 2008 , with $25^{\text {th }}$ percentile at 0.591 and $75^{\text {th }}$ percentile at 1.023 . Michigan experienced greatest range in public opinion at 1.294 , with a low in 1980 and a high in 1990. For states without missing data, New York was among states with the lowest range at 0.586, with a low in 1998 and a high in 1990 . Thus, while states followed the same basic pattern, substantive trends occur for individual states. These trends are likely the result of relative perceptions of environmental program funding, where states with growing proenvironmental support are perceiving a lack of spending. This coincides with observations about the growth of environmental support in the 1980 s as a reaction to perceived anti-environmental policies under the Reagan and Bush administration (Daniels et al., 2013). Additionally, this measure of

\footnotetext{
${ }^{5}$ Data on educational attainment was only available for decennial Censuses.
} 
environmental support is relative to actual environmental expenditures so it is likely effected by both federal and state-level spending. This would further explain why there are general national trends, but state-level variation.

Figure 2. Estimate Trends for Five Randomly Selected States, 1976-2008

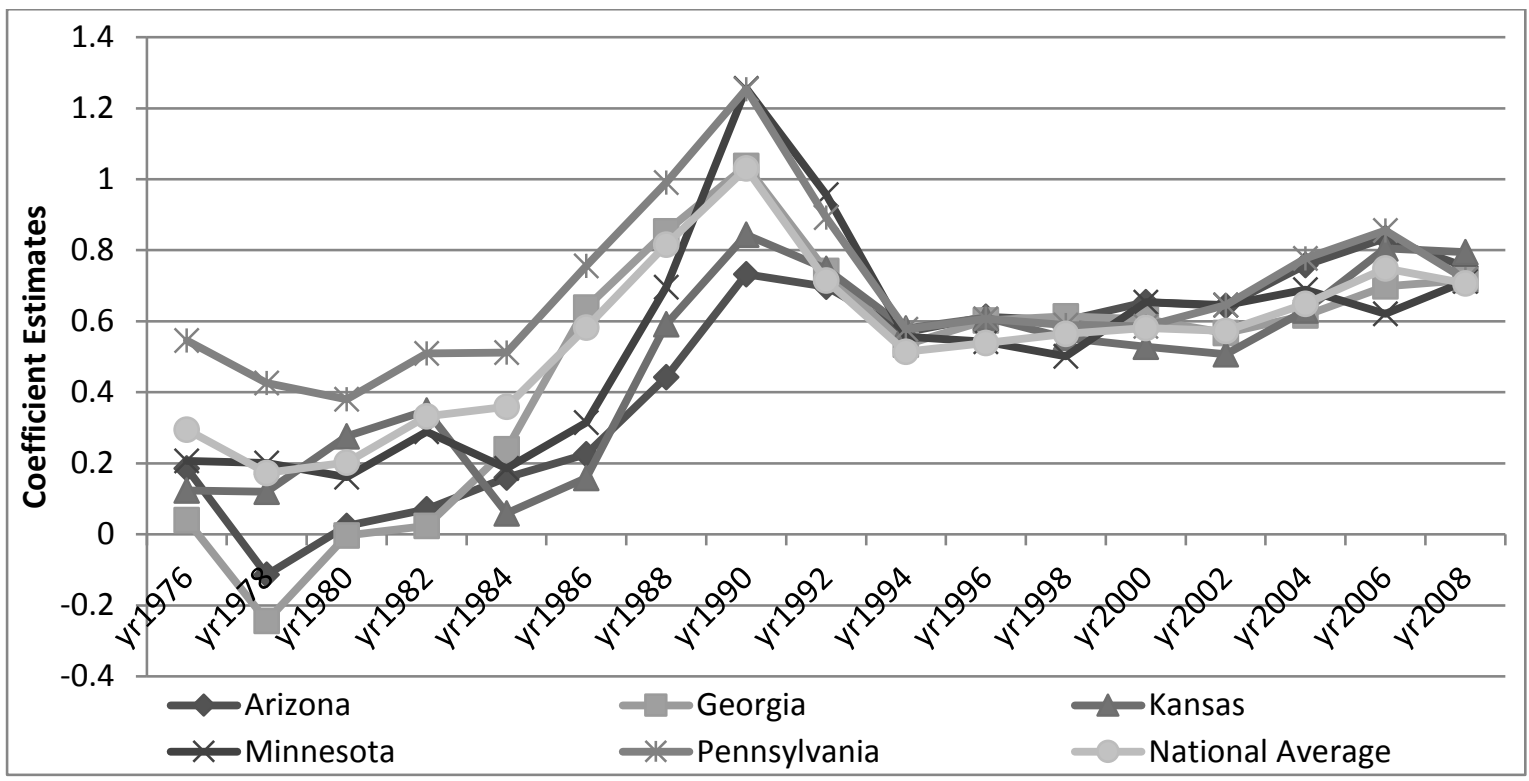

Second, pre-1990 shows a wide gap between states and post-1990 shows a convergence of support. Figure 3 displays a comparison of variance and $25^{\text {th }}$ to $75^{\text {th }}$ percentiles range. Peak range and variance occurred in the mid-1980s, followed by a dramatic decline. The highest range of estimates, 1.164 , occurred in 1984 , showing widest disparity in public opinion, and the lowest range, .330 , occurred in 1994 showing a relative convergence of opinion across states. The average year experienced a 0.501 range of public opinion estimates across states, with $25^{\text {th }}$ percentile at 0.457 and $75^{\text {th }}$ percentile at 0.797. By the early 1990s, both range and variance had decline to less than half of the peak. Since the beginning of the 1990s, both range and variance have remained stable, though. In 1986, at the peak of disparity in range of environmental public opinion, $25^{\text {th }}$ percentile was $.35 ; 50^{\text {th }}$ percentile, .62 ; and $75^{\text {th }}$ 
percentile, .77 . In 2008, at the bottom of disparity in range of environmental public opinion, $25^{\text {th }}$ percentile was $.67 ; 50^{\text {th }}, .71$; and $75^{\text {th }} .75$. Thus, descriptive statistical analysis indicates a substantive change of variation of state-level environmental public opinion over time, with states becoming more homogeneous in their opinions. These trends are likely the result of decreasing disparity in environmental expenditures and conditions across the U.S., where the public is basing their relative perception of environmental spending on their local environmental conditions and federal and state spending levels (EPA, 2008). As local environmental conditions and spending levels become more homogenous, perceptions are following suit.

Figure 3. Variance and $25^{\text {th }}$ and $75^{\text {th }}$ Percentile Range for State Estimates, $1976-2008$

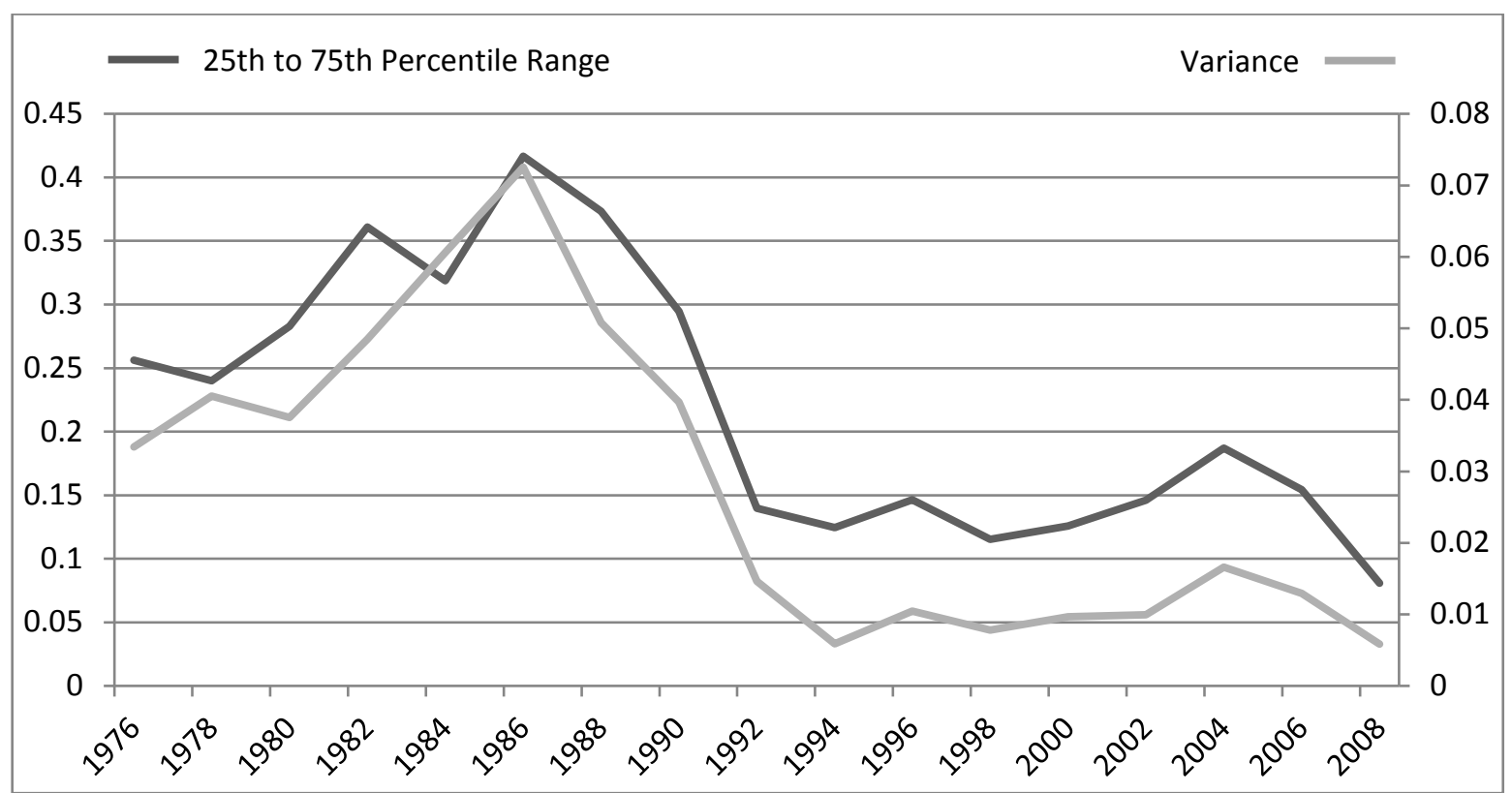

Finally, figures 4 and 5 presents scatterplots of state-level estimates and Republican presidential voting percentage and Berry, Ringquist, Fording, and Hanson (1998)'s measure of citizen liberal ideology from 1976 to 2008 . As the scatterplots indicate, there is a moderately strong negative relationship (Pearson's $r=-.27$ ) for Republican voting percentage, and a strong positive relationship (Pearson's $r=$ .38) for citizen ideology. These relationships are as expected. First, the Republicans tend to be for 
economic development and against government spending, so states supporting the Republican presidential nominee would be unlikely to also support more environmental spending (Daniels et al., 2013) Additionally, there is some indication from previous literature that there is a correlation between environmental support and presidential vote; however, that relationship tends to be weak, and there has been few survey items shown to have a high substantive impact on presidential vote (Daniels et al., 2013). Second, previous scholarship connects both environmentalism and government spending with liberal political ideology, so more liberal states would likely be more supportive of spending on the environment (Erikson and Tedin, 2010; Daniels et al., 2013). Thus, these estimates connect with both voting and ideological patterns as expected and provides some face validity to these public opinion estimates. Additionally, Cronbach's alpha for the public opinion estimates is .997, suggesting there is very high internal consistency to these estimates.

Figure 4. Scatterplot of State Estimates and Republican Presidential Vote Percentage, 1976-2008

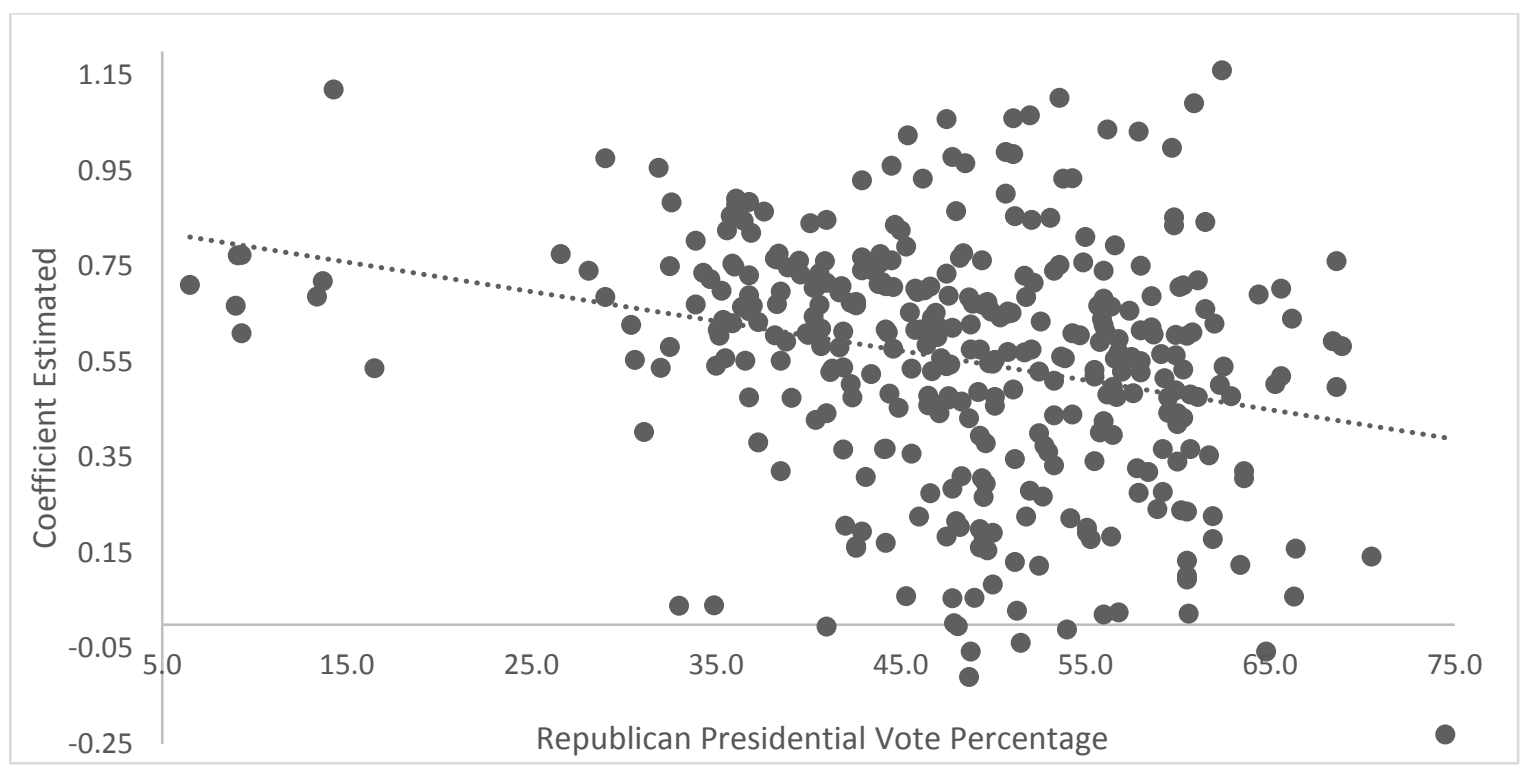


Figure 5. Scatterplot of State Estimates and Citizen Ideology Scores , 1976-2008

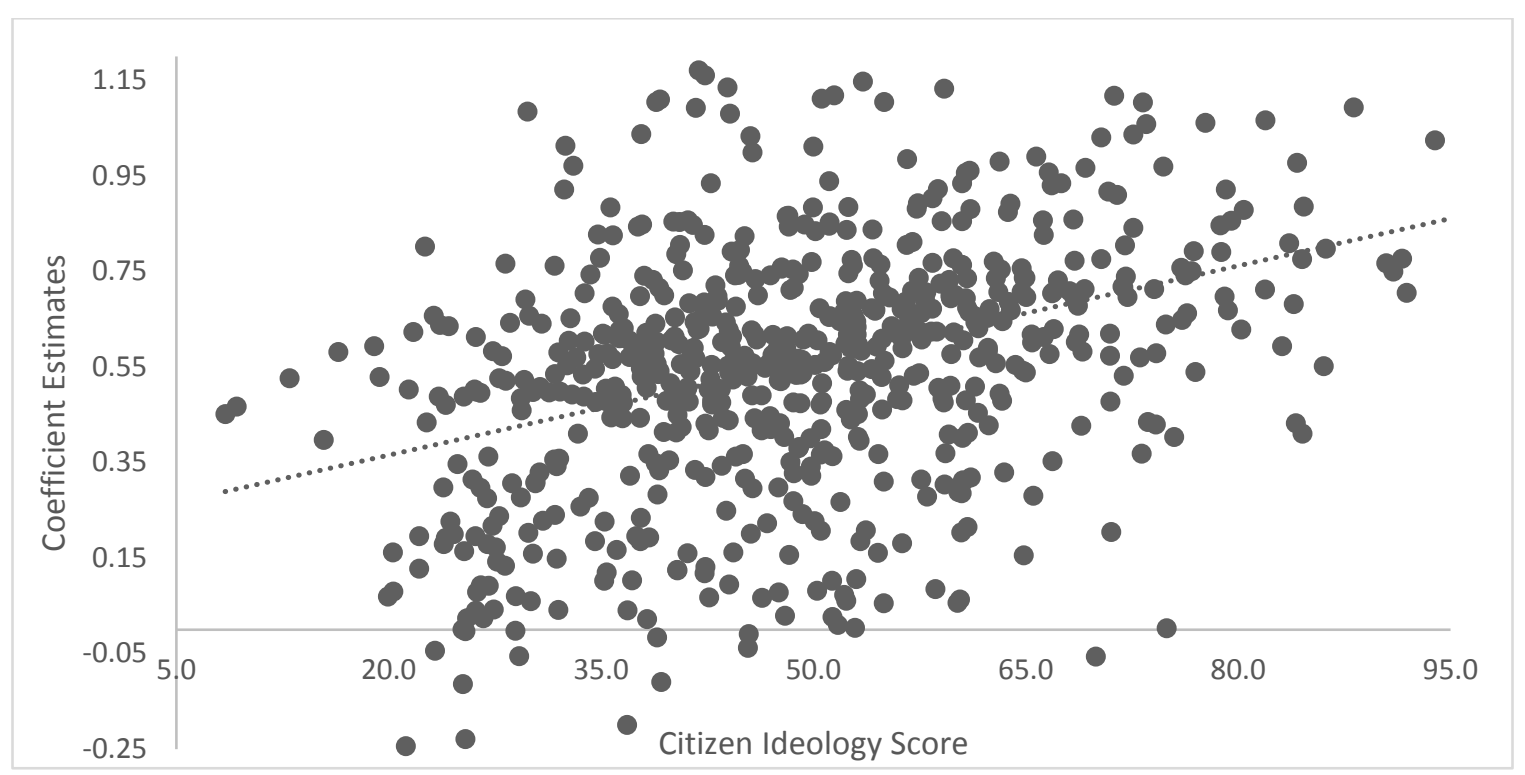

\section{Discussion and Conclusions}

Unsurprisingly, state-level trends on public support of environmentalism follow national trends.

The similar national- and state-level patterns suggest the same issue influencing trends nationally are affecting states in the same way. That is, there has not been a significant polarization split between states on environmental support, like there has been for other social issues (Pacheco, 2014). However, there is enough heterogeneity between states to make the results of interest. States are demonstrating individual trends in environmental support, which deviate from their peers at time. This variability in trends provides an avenue to explore some of the policy and administrative developments that have occurred over the latter half of the $20^{\text {th }}$ century. Identifying these trends can provide insight into why state-level policy processes have experienced disparity over the last several decades, which is key to the public opinion research agenda (Burstein, 2003). Additionally, the findings here likely apply internationally where the expectation should be that lower-level political units will follow the same general trends over time as higher-level counterparts, but the comparative relationship between political units at the same level will not remain the same as variability between units and years occur. 
Further research should explore the connection between trends in public opinion at different political levels, to provide insight into the effects of public opinion on government action.

Additionally, these findings are important in understanding broader trends in environmental policy and administration occurring in the post-1990 era. A substantial amount of scholarship on statelevel environmental actions relies on data from the 1990s and before, and many of these findings suggest either public opinion in general or regional differences in approaches to environmentalism are an explanatory factor in environmental policy and administration (e.g. Johnson, Brace, and Arceneaux, 2005). However, with inter-state homogeneity increasing, those findings may be outdated. For instance, many scholars working with data from the 1980 s and 1990 s utilize a regional variable for Southern states, arguing public environmentalism in the South is different from other regions (e.g. Emison and Morris, 2010). However, with more homogeneity between states, the South may no longer be an outlier region. Therefore, as inter-state homogeneity has increased, scholars need to reconsider previous findings relying on broader assumptions about variability of state-level difference in public environmentalism, and environmental policy and management in the $21^{\text {st }}$ century. Certainly, these findings have application to other areas of public opinion as well. The socio-economic and political antecedents of the convergence of state-level public opinion are likely to be seen in other major public issues. It is also an important observation as political polarization between parties is becoming more pronounced that states are becoming more alike. Thus, it is likely that the polarized debates will become more fervent at the state and local level as opposition to the local traditions grows as regionalism fades and nationalized political culture takes root. Additionally, these methods and observations can be applied to other state-level researchers across policy areas. Certainly, the value of MRP and observations of inter-state homogeneity are not limited to environmentalism.

There are limitations to the findings though. As GSS respondents varied over time, sample size may affect estimates to a certain degree. As observations tend to deviate towards the mean, more 
observations would likely result in estimates clustering and reduced bias from outliers. However, during the peak variance and range from 1984 to 1988, sample sizes were between 6831 and 7177 . On the other hand, during a stretch of base variance and range from 1992 to 1996, samples sizes were between 7076 and 8231 . While sample sizes range is much broader for all estimates, the range representing the extremes is relatively the same. Additionally, this dramatic change occurred around the same time suggesting sample size effects are not masking actual trends in homogeneity. Additionally, not all states are consistently represented in the sample. For 21 states, there is missing data for two or more years. Finally, GSS uses cluster sampling, which can produce biases. Notably for MRP, "if geography matters not only because of interstate variation but also because of intrastate variation, then the accuracy and efficiency of subnational opinion estimates, whether generated through disaggregation or MRP, could be impacted" (Stollwerk, 2012, p. 8). Polling data over several years is one solution, and has been used here. Another solution is to include other level-2 predictors, which some scholars suggest improves accuracy. Only states were used here as level-2 predictors though, as there was little theoretical justification to include others. However, there is still mixed evidence as to how to best overcome the cluster sampling issues with MRP (Stollwerk, 2012). While the existing analysis provides a strong basis to draw conclusions, there are limitations to these observations that should be considered when drawing conclusions. 


\section{References}

Alvarez, R.M., and J. Nagler. 1998. “Economics, Entitlements, and Social Values: Voter Choice in the 1996 Presidential Election." American Journal of Political Science 42: 1349-1363.

Andrews, R.N.L. 2006. Managing the Environment, Managing Ourselves, $2^{\text {nd }}$ ed. New Haven, CT: Yale University Press.

ATS Statistical Consulting Group. 2012. "Introduction to Multilevel Modeling Using HLM 6." University of California - Los Angeles. www.ats.ucla.edu . [accessed October 1, 2014].

Bartels, L.M. 1991. “Constituency Opinion and Congressional Policymaking: The Reagan Defense Buildup." American Political Science Review 85: 457-474.

Berry, W.D., E.J. Ringquist, R.C. Fording and R.L. Hanson. 1998. "Measuring Citizen and Government Ideology in the American States, 1960-93." American Journal of Political Science 42: 327-48.

Bickel, R. 2007. Multilevel Analysis for Applied Research. New York: Guilford.

Bosso, C.J., and D.L. Gruber. 2006. "Maintaining Presence: Environmental Advocacy and the Permanent Campaign." In Environmental Policy, $6^{\text {th }}$ ed., eds. N. Vig and M. Kraft. Washington, DC: CQ Press, 78-99.

Bryk, A.S. and S.W. Raudenbush. 1992. Hierarchical Linear Models. Newbury Park, CA: Sage.

Burstein, P. 2003. "The Impact of Public Opinion on Public Policy: Review and an Agenda." Political Research Quarterly 56: 29-40.

Chaplin, D.D. 2003. "Hierarchical Linear Models: Strengths and Weaknesses." Unpublished Manuscript. Washington, DC: Urban Institute.

Daniels, D.P., J.A. Krosnick, M.P. Tichy, and T. Tompson. 2013. “Public Opinion on Environmental Policy in the United States." In Handbook of U.S. Environmental Policy, eds. M. Kraft and S. Kamieniecki. New York: Oxford University Press, 461-486. 
Davis, F.L., and A.H. Wurth. 2003. "Voting Preferences and the Environment in the American Electorate: The Discussion Extended." Society and Natural Resources 16: 729-740.

Davis, F.L., A.H. Wurth, and J.C. Lazarus. 2008. “The Green Vote in Presidential Elections: Past Performance and Future Promise." Social Science Journal 45: 525-545.

Dunlap, R.E. 1991. "Trends in Public Opinion toward Environmental Issues: 1965-1990." Society and Natural Resources 4: 285-312.

Dunlap, R.E. 1995. "Public Opinion and Environmental Policy." In Environmental Politics and Policy, $2^{\text {nd }}$ ed., ed. J.P. Lester. Durham, NC: Duke University Press, 63-114.

Emison, G.A. and J.C. Morris. 2010. Speaking Green with a Southern Accent. Lanham, MD: Lexington. Environmental Council of the States. 2014. "Delegation by Environmental Act." www.ecos.org. [accessed October 1, 2014].

Erksine, H. 1972. "The Polls: Pollution and Its Costs." Public Opinion Quarterly 35: 120-135.

Erikson, R.S., and K.L. Tedin. 2010. American Public Opinion, $8^{\text {th }}$ ed. New York: Pearson.

Fowler, L. and J. Breen. 2013. "The Impact of Political Factors on States' Adoption of Renewable Portfolio Standards." The Electricity Journal 26: 79-94.

Fowler, L. and J. Breen. 2014). "Political Influences and Financial Incentives for Renewable Energy." The Electricity Journal 27: 74-84.

Fowler, L. 2016. "The States of Public Opinion on the Environment." Environmental Politics 25: 315-337. Gelman, A. and T.C. Little. 1997. "Poststratification into Many Categories Using Hierarchical Logistic Regression." Survey Methodology 23: 127-35.

Hanemann, W.M. 2007. "How California came to Pass AB 32, the Global Warming Solutions Act of 2006." University of California Department of Agricultural and Resource Economics working paper no. 1040. 
Hofmann, D.A. 1997. "An Overview of the Logic and Rationale of Hierarchical Linear Models." Journal of Management 23: 723-744.

Hoornbeek, J.A. 2005. "The Promises and Pitfalls of Devolution: Water Pollution Policies in the American States." Publius 35: 87-114.

Johnson, M., P. Brace, and K. Arceneaux. 2005. "Public Opinion and Dynamic Representation in the American States: the Case of Environmental Attitudes." Social Science Quarterly 86: 87-108.

Ladd, E.C., and K.H. Bowman. 1995. Attitudes toward the Environment. Washington, DC: American Enterprise Institute Press.

Lax, J.R. and J.H. Phillips. 2009a. "Gay Rights in the States: Public Opinion and Policy Responsiveness." American Political Science Review 103: 367-386.

Lax, J.R. and J.H. Phillips. 2009b. "How Should We Estimate Public Opinion in the States?" American Journal of Political Science 53: 107-121.

Lowery, D., V. Gray, and F.R. Baumgartner. 2011. “Policy Attention in State and Nation: Is Anyone Listening to the Laboratories of Democracy?" Publius 41: 286-310.

Nordhaus, T. and M. Shellenberger. 2007. Break Through. New York: Houghton Mifflin.

Pacheco, J. 2011. “Using National Surveys to Measure Dynamic U.S. State Public Opinion: A Guideline for Scholars and an Application." State Politics and Policy Quarterly 11: 415-439.

Pacheco, J. 2014. "Measuring and Evaluating Changes in State Opinion across Eight Issues." American Politics Research 42: 986-1009.

Park, D.K, A. Gelman and J. Bafumi. 2006. "State-level Opinions from National Surveys: Poststratification Using Multilevel Logistic Regress." In Public Opinion in State Politics, ed. J. Cohen. Stanford, CA: Stanford University Press, 209-228. 
Rabe, B. 2013. "Racing to the top, bottom, or the middle of the pack? The evolving state government role in environmental protection." In Environmental Policy, $9^{\text {th }}$ ed., eds. N.J. Vig and M.E. Kraft. Washington, D.C.: CQ Press/Sage, 30-53.

Raudenbush, S.W., and A.S. Bryk. 2002. Hierarchical Linear Models, 2nd ed. Thousand Oaks, CA: Sage.

Repetto, R. 2006. "Introduction to Punctuated Equilibrium and the Dynamics of U.S. Environmental Policy." In Environmental Policy, ed. R. Repetto. New Haven, CT: Yale University Press, 1-23.

Ringquist, E.J. 1993. Environmental Protection at the State Level. Armonk, NY: M.E. Sharpe.

Sapat, A. 2004. "Devolution and Innovation: The Adoption of State Environmental Policy Innovations by Administrative Agencies." Public Administration Review 64: 141-151.

Shipan, C.R., and C. Volden. 2012. "Policy Diffusion: Seven Lessons for Scholars and Practitioners." Public Administration Review 72: 788-796.

Smith, T.W, P. Marsden, M. Hout, and J. Kim. 2013. General Social Surveys, 1972-2012: Cumulative Codebook. Chicago: National Opinion Research Center.

Stimson, J.A., M.B. Mackuen, and R.S. Erikson. 1995. Dynamic Representation. The American Political Science Review 89(3): 543-565.

Stollwerk, A. 2012. Estimating Subnational Opinion with Cluster-Sampled Polls: Challenges and Suggestions. Paper presented at 2012 American Political Science Association Annual Conference, New Orleans, LA.

Tarr, G.A. 2001. "Laboratories of Democracy? Brandeis, Federalism, and Scientific Management." Publius 31: $37-46$.

U.S. Census. 2016. U.S. Census Abstract of the States. www.census.gov. [accessed February 1, 2016].

U.S. Environmental Protection Agency. 2008. EPA'S Report on the Environment. Washington, DC: Government Printing Office. 
Volden, C. 2006. "States as Policy Laboratories: Emulating Success in the Children's Health Insurance Program." American Journal of Political Science 50: 294-312.

Warshaw, C. and J. Rodden. 2012. "How Should We Measure District-level Public Opinion on Individual Issuefs?" Journal of Politics 74: 203-219.

Woods, N.D. 2006. "Primacy Implementation of Environmental Policy in the US States." Publius 36: 259276. 
Appendix A. Missing Data by State and Year

\begin{tabular}{|l|l|l|l|}
\hline State & Missing Years & State & Missing Years \\
\hline Alaska & $1976-1990 ; 2006-2008$ & Nevada & $1976-2008$ \\
Arkansas & $1998-2000$ & New Hampshire & $1976-1980 ; 1994-2008$ \\
Delaware & $1976-1990$ & New Mexico & $1976-2000$ \\
Hawaii & $1976-2000$ & North Dakota & $1976-1980 ; 2006-2008$ \\
Idaho & $1976-2000$ & Rhode Island & $1976-1980 ; 1994-2008$ \\
lowa & $1994-2000$ & South Dakota & $1976-1990 ; 2006-2008$ \\
Kentucky & $1976-1980$ & Utah & $1976-1980 ; 1994-2008$ \\
Maine & $1976-2000$ & Vermont & $1976-1990 ; 2006-2008$ \\
Mississippi & $1976-1980 ; 2006-2008$ & West Virginia & $1996-2000$ \\
Montana & $1986-1990 ; 2006-2008$ & Wyoming & $1976-1980 ; 1994-2000$ \\
Nebraska & $1976-2008$ & & \\
\hline
\end{tabular}

